\title{
Erosion of tungsten-doped amorphous carbon films in oxygen plasma
}

\author{
P. Wang, W. Jacob ${ }^{*}$, M. Balden, A. Manhard, T. Schwarz-Selinger \\ Max-Planck-Institute für Plasmaphysik, EURATOM Association, Boltzmannstr. 2, 85748 Garching,
}

Germany

\begin{abstract}
:
Tungsten-doped amorphous carbon films with 0-9 at.\% W concentration were produced by magnetron sputtering and eroded in oxygen plasmas applying different bias voltages and substrate temperatures. The partial $\mathrm{C}$ and $\mathrm{W}$ erosion rates were determined from the $\mathrm{C}$ and $\mathrm{W}$ areal density changes measured by Rutherford backscattering spectrometry (RBS). The initial C removal rate increases with increasing ion energy and temperature and decreases with increasing $\mathrm{W}$ concentration. For $\mathrm{W}$-doped films the erosion rate decreases with increasing plasma exposure duration. At low bias voltages the erosion process stops after $\mathrm{W}$ accumulation at the surface, which protects the carbon underneath from further erosion. RBS and X-ray photoelectron spectroscopy suggest that the Wrich layer at the surface is carbon free and consists of porous $\mathrm{WO}_{3}$. Biasing to $200 \mathrm{~V}$ leads to removal of $\mathrm{W}$ by physical sputtering and, therefore, inhibits the formation of the protecting $\mathrm{W}$ oxide layer and the $\mathrm{C}$ erosion proceeds.
\end{abstract}

Keywords: Amorphous carbon films, Tungsten-doped carbon, Erosion, Oxygen plasma PACS: $52.40 . \mathrm{Hf}, 81.65 . \mathrm{Cf}, 81.65 . \mathrm{Mg}, 82.65 .+\mathrm{r}$

Published in:

Journal of Nuclear Materials, 420, 101-109 (2011). doi:10.1016/j.jnucmat.2011.09.023

\footnotetext{
${ }^{*}$ Corresponding author. Fax:+49-3299-1504, Tel:+49-3299-2618.

E-mail address: wolfgang.jacob@ipp.mpg.de
} 


\section{Introduction}

The erosion of plasma-facing materials (PFM) is an inevitable consequence of the interaction between a magnetically confined fusion plasma and its adjacent solid surfaces. For the next step, the international fusion experimental device ITER, it is planned to use in different areas of the first wall beryllium, tungsten (W) and carbon (C) as PFM [1]. With this material choice, erosion and re-deposition of carbon accompanied by co-deposition of hydrogen isotopes is expected to be the dominant tritium retention mechanisms [1-3]. To avoid continuous build-up of a fuel inventory inside the vacuum vessel, a variety of techniques for regular tritium removal have been proposed. These techniques include glow discharge cleaning [4-8], thermal oxidation [9] and laser and flash lamp ablation techniques [10]. Among these techniques, oxygen glow discharge cleaning was proven as one promising candidate to remove re-deposited layers. For example, ASDEX Upgrade showed that removal is very effective even at room temperature and similar results were obtained in TEXTOR and HT-7 for elevated temperatures [4-8]. Schwarz-Selinger et al. [11,12] have recently shown that oxygen plasmas are very efficient for removal of hydrocarbon films which are a good model system for re-deposited carbon films in fusion devices. This is true not only for plasma exposed areas [11], but at elevated surface temperatures $(>400 \mathrm{~K})$ also for areas which have no direct line of sight to the cleaning discharge such as, e.g., in tile gaps.

So far, most laboratory plasma experiments were focused on the erosion of pure carbon and hydrocarbon films in oxygen or oxygen containing gas mixtures. However, the use of carbon together with metallic materials in fusion devices will lead to redeposition of metal containing carbon films. Therefore, the erosion behavior of such mixed layers needs to be investigated. Moreover, a reduction of the chemical erosion of carbon by doping has been reported, but is still not fully understood [13-15] (for a review of this field see [16]). Hence, metal-doped carbon films represent a model system to investigate the erosion of redeposited carbon films by oxygen plasmas. The present study focuses on the effect of tungsten doping on the erosion behavior by oxygen plasmas. Tungsten-doped amorphous carbon $(a-\mathrm{C}: \mathrm{W})$ films were deposited by magnetron sputtering and then eroded in low-temperature oxygen plasmas. The erosion behavior was investigated as a function of substrate temperature, ion energy, tungsten concentration and thickness of the films.

\section{Experimental details}

Pure and tungsten-doped amorphous carbon films were deposited onto single crystalline (100) silicon wafers using a commercial sputtering device (Discovery ${ }^{\circledR} 18$, Denton) comprising three individually controllable magnetrons. For the deposition of $a$ $\mathrm{C}: \mathrm{W}$ films two of these magnetrons were used, one holding a graphite and the other a tungsten target. Argon was used as sputtering gas. The rf power applied to the graphite target was held constant at $500 \mathrm{~W}$, and the dc power applied to the tungsten target was varied from 0 to $10 \mathrm{~W}$ to produce pure carbon films and tungsten-doped carbon films with different tungsten concentration. No extra substrate bias and heating were applied during deposition. More details of the deposition procedure can be found in Ref. [17], and an overview of the layer properties in Refs $[18,19]$.

Rutherford backscattering spectrometry (RBS) was applied to measure the elemental composition of the films before and after erosion. A beam of $4.0 \mathrm{MeV}{ }^{4} \mathrm{He}$ was used at a scattering angle of $165^{\circ}$, and a charge of $15 \mu \mathrm{C}$ was usually accumulated for one RBS spectrum. In some cases, a $70^{\circ}$ degree incidental angle instead of normal incidence to the surface was applied in RBS analysis to enhance the sensitivity for thin 
films at the surface. The spectra were simulated using the program SIMNRA 6.05 [20]. The film composition is determined in atomic percent. The tungsten concentration of the film varies between 0 and 9 at. \%. For convenience, the notation being used throughout the text to describe a tungsten-doped amorphous carbon films containing $\mathrm{x}$ at.\% tungsten is " $\mathrm{x} \% \mathrm{a}-\mathrm{C}: \mathrm{W}$ ".

RBS measures the areal density (atoms $/ \mathrm{cm}^{2}$ ) of elements in the films. In order to calculate the thickness of films in nanometer the density has to be known. To independently determine the density the mass change of a complete silicon wafer ( 4 inch in diameter) due to deposition of the $a-\mathrm{C}$ film was measured by a microbalance and the film thickness was determined by profilometry. This yields a carbon number density of $8.48 \times 10^{28}$ atoms $/ \mathrm{m}^{3}$, corresponding to a mass density of $1.67 \mathrm{~g} / \mathrm{cm}^{3}$. This value is in excellent agreement with the value determined from RBS and the layer thickness. For comparison, the mass density and carbon number density of graphite are $2.26 \mathrm{~g} / \mathrm{cm}^{3}$ and $11.4 \times 10^{28}$ atoms $/ \mathrm{m}^{3}$, respectively.

X-ray photoelectron spectroscopy (XPS) was carried out on a PHI5600 system using an Al Ka source. The photoelectron spectra were measured with a hemispherical analyzer operating at a pass energy of $23.5 \mathrm{eV}$. The binding energy scale was calibrated with the $\mathrm{Au} 4 \mathrm{f}_{7 / 2}$ peak at $84.0 \mathrm{eV}$, the $\mathrm{Cu} 2 \mathrm{p}_{3 / 2}$ peak at $932.7 \mathrm{eV}$, and the $\mathrm{Ag} 3 \mathrm{~d}_{5 / 2}$ peak at $368.3 \mathrm{eV}$. Depth profiles were acquired by sputtering with a scanning $3 \mathrm{keV} \mathrm{Ar}{ }^{+}$ion beam. The sputtered area was about $1 \times 1 \mathrm{~mm}^{2}$, and the ion beam current on the target was about $20 \mathrm{nA}$ (corresponding to a flux of $1.2 \times 10^{17} \mathrm{~m}^{-2} \cdot \mathrm{s}^{-1}$ ).

Erosion experiments were carried out in the low-temperature plasma experiment PlaQ. A basic description of PlaQ is given in Refs. [21,22]. In short, PlaQ consists of a stainless steel chamber and is equipped with a remote electron cyclotron resonance (ECR) plasma source. Microwaves $(2.45 \mathrm{GHz})$ are coupled into the vacuum vessel from the high B-field side through a waveguide terminated by a quartz window. The magnetic field is created by a single magnetic coil. To decouple the plasma from the substrate, the plasma is confined in a metallic cage $150 \mathrm{~mm}$ height and $140 \mathrm{~mm}$ diameter. Particles can leave the cage in an axial direction through a hole in the bottom plate with a diameter of $55 \mathrm{~mm}$. A diverging plasma beam impinges perpendicularly onto the substrates which are located $100 \mathrm{~mm}$ below the cage exit. The energy of the ions impinging on the substrates can be varied by applying a dc or $\mathrm{rf}$ bias to the substrate electrode. In the experiments reported here rf bias was used. The application of an rf voltage to the substrate electrode causes the formation of a dc self-bias voltage $\left(\mathrm{V}_{\mathrm{SB}}\right)$ such that the substrate holder is always negative relative to the plasma potential. The bias voltages given in this article are these dc self-bias voltages created by the application of rf power. Due to the polarity they are quoted as negative numbers. The corresponding mean ion energy is approximately the sum of the absolute values of the dc self-bias voltage and the plasma potential. To ensure identical conditions in all erosion processes, the microwave output power for the ECR plasma was set to $150 \mathrm{~W}$ with a constant $\mathrm{O}_{2}$ gas pressure prior to plasma ignition of $0.5 \mathrm{~Pa}$ (gas flow $20 \mathrm{sccm}$ ).

To measure the mass-integrated ion flux as well as the energy of the ions impinging on the substrate for a given condition, the substrate holder was replaced by a mock-up sample holder that incorporates a differentially pumped retarding-field analyzer (RFA). Details about the setup are described in Ref. [22]. From the known size of the sampling aperture $(100 \mu \mathrm{m})$ and the geometrical transmission of the repeller grid inside the analyzer $(75 \%)$ the absolute flux density was determined. For $0.5 \mathrm{~Pa}$ and the nominal ECR power of 150 Watts the total ion flux is $5.8 \times 10^{22}$ atoms $\mathrm{m}^{-2} \mathrm{~s}^{-1}$. The ion flux distribution is shown in Fig. 1. At floating potential the ion flux distribution starts to increase at about $5 \mathrm{eV}$. It reaches its maximum at $11 \mathrm{eV}$, has a high energy shoulder at 
about $18 \mathrm{eV}$, and extends to about $23 \mathrm{eV}$. The full width at half maximum of the main peak is $5.4 \mathrm{eV}$.

The mass distribution of the ions impinging at the substrate position was measured with an energy selective mass spectrometer (Hiden Analytical EQP 300). In this case ions are sampled through a $(250 \mu \mathrm{m})$ hole in the substrate holder dummy left at floating potential. The EQP consists of an ion extraction and focusing optic, a $45^{\circ}$ electrostatic energy analyser and a quadrupole mass spectrometer. Ions were detected with a faraday cup to assure temporal stability. Details about the setup are described in Ref. [23]. Consecutive analogue mass spectra were scanned with a step width of $0.05 \mathrm{amu}$ increasing the energy from scan to scan by $0.1 \mathrm{eV}$. For $0.5 \mathrm{~Pa}$ and the nominal ECR power of $150 \mathrm{~W}$ the ion flux consists mainly of $\mathrm{O}_{2}{ }^{+}$ions $(\sim 86 \%)$ with minor contributions of $\mathrm{O}^{+}(\sim 14 \%)$. The mass transmission probability for these 2 oxygen ions was assumed to be equal. This ion mass distribution has to be taken into account when assessing the interaction of these ions with the surface. The energy distributions of the two species are by and large identical. In particular both ion species show the main peak and the high energy shoulder so that the two different peaks cannot be attributed to the two different ion species, but are due to the electric field structure in the plasma sheath.

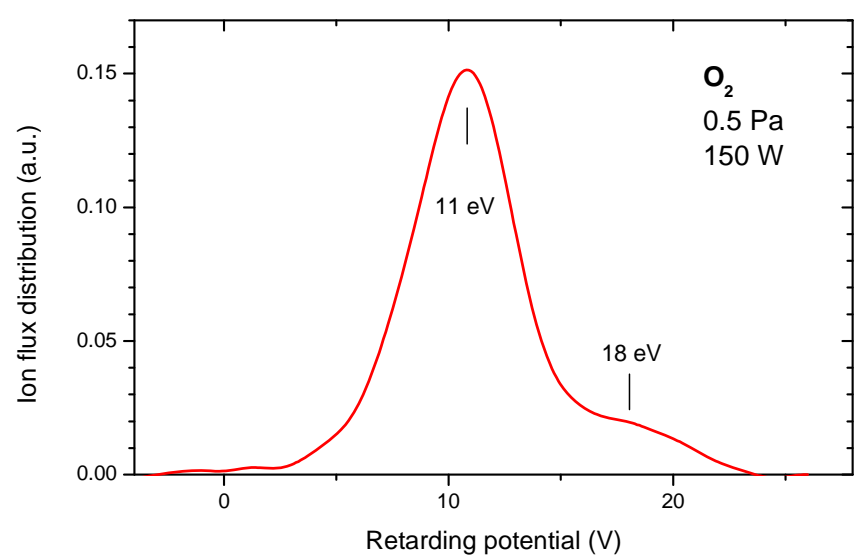

Fig. 1: Ion flux distribution measured with the retarding field analyzer in an oxygen plasma (0.5 $\mathrm{Pa}, 150 \mathrm{~W})$ for a floating substrate holder.

To investigate the erosion process at different conditions, two substrate holders a cooled and a heated one were applied. The cooled substrate holder was used to eliminate the effect of heating the targets by ion bombardment during plasma exposure. It is equipped with an open circuit thermostat using silicon oil to stabilize the sample holder at room temperature if $\mathrm{rf}$ bias was applied. The temperature of the heated substrate holder can be increased from room temperature to $950 \mathrm{~K}$ by a BORALECTRIC ${ }^{\circledR}$ heating element [24] mounted inside the substrate holder. The heating power was feedback controlled by an infrared camera focused on the surface of the substrate holder.

Further, PlaQ is equipped with in situ ellipsometry, so the optical response from the sample due to plasma exposure can be measured in real-time at the fixed wavelength of $632.8 \mathrm{~nm}$. This method was successfully used to determine the deposition and erosion rates of hydrogenated amorphous carbon films in different plasmas using oxygen, hydrogen and different gas mixtures as working gases [21]. Unfortunately, metal-doped carbon films are a more complicated system. A quantitative analysis of the raw data is at present not possible because not only the optical constants but also the layer structure of the surface layer of the films change during the erosion and the corresponding film 
thicknesses and the optical constants of the different layers are presently unknown. Furthermore, amorphous carbon material prepared by magnetron sputtering of a graphite target consists of nano-graphite particles dispersed in an amorphous carbon matrix $[12,25,26]$, and therefore it is strongly absorbing at the laser wavelength of $623.8 \mathrm{~nm}$. As a consequence, time-resolved erosion rates could not be deduced from real-time ellipsometry measurements.

Even though ellipsometry could not be used to resolve the real-time erosion rates, changes of the films due to plasma exposure could be detected. Applying ellipsometry to determine the beginning and the end of the erosion process allowed setting appropriate plasma exposure durations. In this article, the erosion yields of the films were predominantly determined by Rutherford backscattering spectrometry. The carbon and tungsten amounts were measured before and after erosion by the oxygen plasma. Then the averaged erosion rates were calculated by dividing the amount of removed carbon or tungsten atoms by the elapsed erosion time.

In order to detect morphological changes cross-sections of the plasma-exposed films were imaged with scanning electron microscopy (SEM). The used microscope (Helios NanoLab 600, FEI) allows the cross-sectioning in situ by the implemented focused ion beam (FIB). The secondary electrons produced by a $5 \mathrm{keV}$ electron beam were detected by the inlens detector system. The SEM images of the cross-sections were recorded with the e-beam tilted by $38^{\circ}$ to the normal axis of the image plane, so that the vertical scale in the shown images is compressed relative to the horizontal scale.

Before the cross-sectioning by FIB, the specimens were covered with a roughly $1 \mu \mathrm{m}$ thick $\mathrm{Cu}$ layer deposited by magnetron sputtering without substrate bias and heating. This coating leads to a clear contrast between a-C:W film and the $\mathrm{Cu}$ coating, which is necessary to obtain sufficiently flat cross-sections.

\section{Results and discussion}

In a first set of experiments pure and 1.8 at.\% tungsten containing amorphous carbon films with a thickness of $100 \mathrm{~nm}$ were eroded in an oxygen plasma. The effect of substrate temperature and ion energy on the erosion rate was investigated. In these experiments ellipsometry was used to determine the end point of carbon erosion. Although, as discussed in the preceding section, ellipsometry cannot be used to measure the real-time erosion rates, the end point can be clearly identified by ellipsometry. After erosion, Rutherford backscattering spectrometry was applied to determine the remaining $\mathrm{C}$ content. It turned out that all carbon in the $\mathrm{a}-\mathrm{C}: \mathrm{W}$ film was removed. The time-averaged carbon and tungsten removal rates for these measurements were calculated from the removed $\mathrm{C}$ and $\mathrm{W}$ amounts and the time elapsed between start of the erosion and the end-point. 


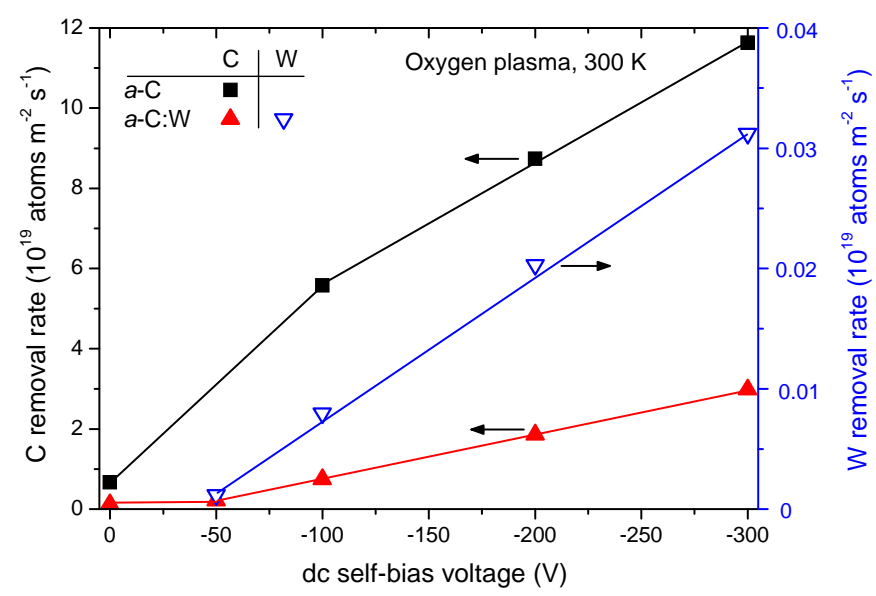

Fig. 2: Erosion rate of pure and $1.8 \%$ a-C:W films as a function of $d c$ self-bias voltage voltage at $300 \mathrm{~K}$ substrate temperature in an oxygen plasma. The left-hand scale shows the carbon removal rate (filled symbols) and the right-hand scale for the tungsten removal rate (open symbols). Note the different scales.

Fig. 2 shows the time-averaged carbon removal rates of $a-\mathrm{C}$ and $1.8 \% a-\mathrm{C}: \mathrm{W}$ films as a function of the dc self-bias voltage $\left(\mathrm{V}_{\mathrm{SB}}\right)$ and the corresponding tungsten removal rate of $1.8 \% a-\mathrm{C}: \mathrm{W}$ films. During the whole erosion process, the substrate temperature was kept at $300 \mathrm{~K}$ using the cooled substrate holder. The erosion rate of the films depends strongly on $\mathrm{V}_{\mathrm{SB}}$. Fig. 2 shows that the time-averaged carbon removal rate of the $a$-C film is $0.7 \times 10^{19}$ atoms $\cdot \mathrm{m}^{-2} \cdot \mathrm{s}^{-1}$ at floating potential (corresponding to about $11 \mathrm{eV}$ ion energy, see section 2). It increases by a factor of 17 to $11.6 \times 10^{19}$ atoms $\cdot \mathrm{m}^{-2} \cdot \mathrm{s}^{-}$ ${ }^{1}$ if $\mathrm{V}_{\mathrm{SB}}$ is increased to $-300 \mathrm{~V}$. This increase is monotonic and no saturation occurs in the whole investigated range.

The influence of $\mathrm{V}_{\mathrm{SB}}$ on the $\mathrm{C}$ and $\mathrm{W}$ removal rates for $a-\mathrm{C}$ : $\mathrm{W}$ films shows a similar increase compared to that of $a-\mathrm{C}$ but the yields are much lower. Although doped with only $1.8 \%$ tungsten, the time-averaged carbon removal rate of $a-\mathrm{C}: \mathrm{W}$ films is about $0.12 \times 10^{19}$ atoms $\cdot \mathrm{m}^{-2} \cdot \mathrm{s}^{-1}$ at floating potential and about $2.98 \times 10^{19}$ atoms $\cdot \mathrm{m}^{-2} \cdot \mathrm{s}^{-1}$ at $-300 \mathrm{~V}$, i.e., it drops in this range by about a factor of 4 to 5 compared with pure $a-C$ films. No tungsten atoms are removed at floating potential due to the low energy of ions, in this case only $11 \mathrm{eV}$ (see section 2), which is below the threshold of physical sputtering of tungsten by oxygen (about $44 \mathrm{eV}$ [27]). Between -50 and $-300 \mathrm{~V}$ the $\mathrm{C}$ and $\mathrm{W}$ removal rates increase by a factor of 14 and 26 , respectively.

The variation of the time-averaged carbon removal rate with substrate temperature is shown in Fig. 3 in form of an Arrhenius plot. The pure $a-\mathrm{C}$ as well as the $1.8 \% a$ $\mathrm{C}: \mathrm{W}$ film both show an Arrhenius-type behavior with an apparent activation energy of 0.09 and $0.17 \mathrm{eV}$, respectively. These values of the apparent activation energies are remarkably low. Firstly, the activation energy for $a-\mathrm{C}$ film is much lower than that for oxidative removal of graphitic materials in an oxygen atmosphere, which is about $1.7 \mathrm{eV}$ [28]. This is not too surprising since an oxygen plasma is a source for species with a much higher reactivity than stable ground state oxygen molecules. Secondly, this value is also significantly lower than that found for oxygen glow discharge removal of plasma-deposited amorphous hydrogenated carbon $(a-\mathrm{C}: \mathrm{H})$ films in plasma-shaded areas $(0.25 \mathrm{eV}[12])$. Thirdly, the $1.8 \% a-\mathrm{C}: \mathrm{W}$ films has a higher apparent activation energy than the pure $a-\mathrm{C}$ film and shows, therefore, a larger resilience against oxidation than the pure $\mathrm{C}$ film. 


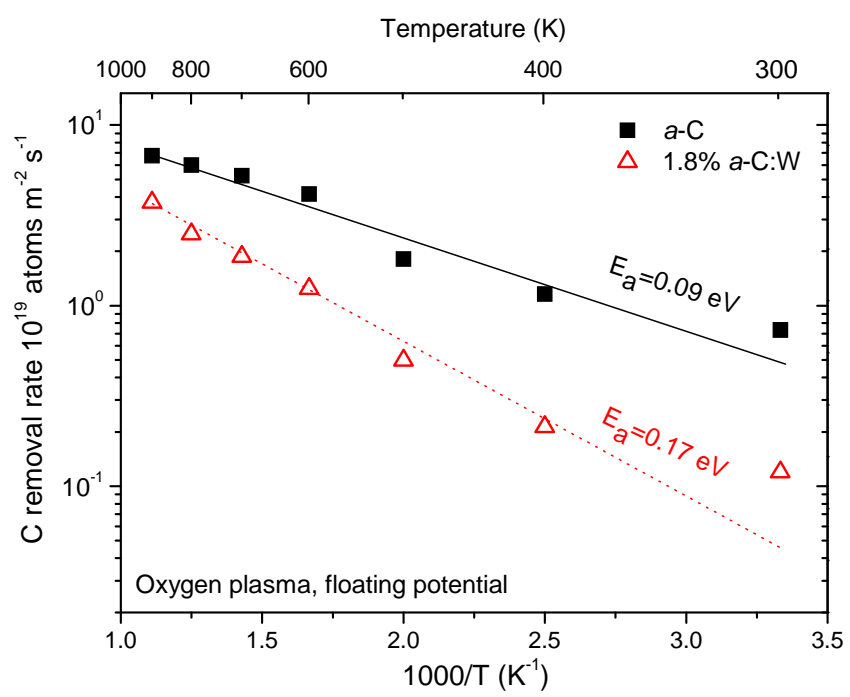

Fig. 3: Carbon removal rate of pure (filled symbols) and $1.8 \%$ a-C:W (open symbols) films as a function of substrate temperature at floating potential in oxygen plasma. Data are shown in the form of an Arrhenius plot as a function of inverse temperature in logarithmic scale. Lines represent Arrhenius functions with the given activation energies.

The above results show that doping of carbon with a small amount of tungsten can substantially decrease the erosion rate by an oxygen plasma. To gain further insight into the effect of tungsten doping, $a-\mathrm{C}: \mathrm{W}$ films with different thicknesses and different tungsten concentrations were prepared and eroded in oxygen plasmas. In these experiments the substrate temperature during erosion was set to $600 \mathrm{~K}$ to accelerate the erosion process.

In order to study the effect of the film thickness on the erosion of $a-\mathrm{C}: \mathrm{W}$ films, a $250 \mathrm{~nm}$ thick pure carbon film and $1.8 \% a-\mathrm{C}: \mathrm{W}$ films with different thicknesses up to $300 \mathrm{~nm}$ were eroded in an oxygen plasma. Fig. 4 shows the removed carbon amount as a function of exposure duration with the sample at floating potential. For the pure carbon film (solid squares) the removed carbon amount increases linearly with increasing exposure time. This is the anticipated behavior for an erosion process with constant erosion rate. The complete $250 \mathrm{~nm}$ thick film is eroded after an exposure time of about $11 \mathrm{~min}$ yielding a removal rate of $23 \mathrm{~nm} / \mathrm{min}$. The three $1.8 \% a-\mathrm{C}: \mathrm{W}$ films show this linear behavior only for the first $100 \mathrm{~nm}$. Compared with the pure $a-C$ film the following two differences are found: First, the carbon removal rate for the W-doped films is significantly lower than that of the $a-\mathrm{C}$ film. This result is in excellent agreement with the data presented in Fig. 2. Second, the removal rate is not constant, but decreases with increasing exposure duration. The removed $\mathrm{C}$ amount of the $100 \mathrm{~nm}$ film can still be described by a straight line, the $200 \mathrm{~nm}$ film shows already a deviation towards the end of erosion process which is continued by the $300 \mathrm{~nm}$ film. The three dotted lines in Fig. 4 which connect the end point of the three $a-C: \mathrm{W}$ films with the origin clearly show that the removal rates for the three films decrease with increasing exposure duration. 


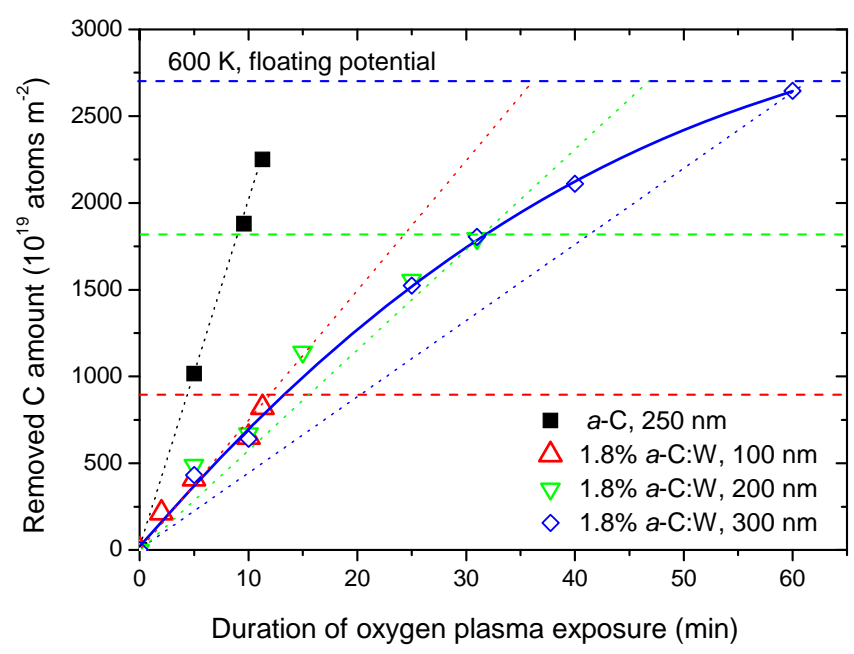

Fig. 4: Removed carbon amount of $1.8 \%$ a-C:W films as a function of erosion duration at floating potential and $600 \mathrm{~K}$ sample temperature. For comparison, data from a $250 \mathrm{~nm}$ pure carbon film (filled symbols) are also presented. The initial carbon amounts of the three a-C:W films with different thicknesses are indicated by the horizontal dashed lines. The dotted lines connect the origin with the endpoints of the three different films. The solid line is a guide to the eye.

We interpret this deceleration of the removal process by an accumulation of a Wrich layer at the surface which leads to a decrease of the removal efficiency with increasing time. Since these experiments were performed at floating potential the ion energy is too low to cause sputtering of $\mathrm{W}$ atoms from the surface. As a consequence, all the $\mathrm{W}$ atoms that were present in the original layer should remain in this $\mathrm{W}$-rich layer at the surface. The total $\mathrm{W}$ amounts for these three different samples are $1.5 \times 10^{20}$ atoms $/ \mathrm{m}^{2}, 3.0 \times 10^{20}$ atoms $/ \mathrm{m}^{2}$, and $4.6 \times 10^{20}$ atoms $/ \mathrm{m}^{2}$. If we would assume that $\mathrm{W}$ is present in form of a compact bulk $\mathrm{W}$ film the corresponding thicknesses would be 2.4, 4.8 and $7.3 \mathrm{~nm}$. Davis et al. reported that a sputter-deposited 1-2 monolayer thick compact tungsten layer on $a-\mathrm{C}: \mathrm{D}$ films can significantly decrease the erosion rate of the film by baking in an oxygen atmosphere at $623 \mathrm{~K}$ and a 8-12 monolayer thick tungsten film (corresponding to about 3-4 nm) stops erosion completely [29]. Similarly, it is hard to believe that in our case plasma erosion continues through a 2 to $7 \mathrm{~nm}$ thick solid tungsten film. Therefore, we assume that the W-rich layer formed at the surface is not compact but porous with a sufficiently high open porosity to allow transmission of reactive oxygen species and the release of the erosion products $\left(\mathrm{CO}\right.$ and $\left.\mathrm{CO}_{2}\right)$ [4]. Additionally, we will show further below that the $\mathrm{W}$-rich layers are actually $\mathrm{W}$ oxide layers. Since the density of $\mathrm{W}$ oxide is much lower than that of bulk tungsten, the $\mathrm{W}$ oxide films remaining after erosion are much thicker than a few nanometres. 


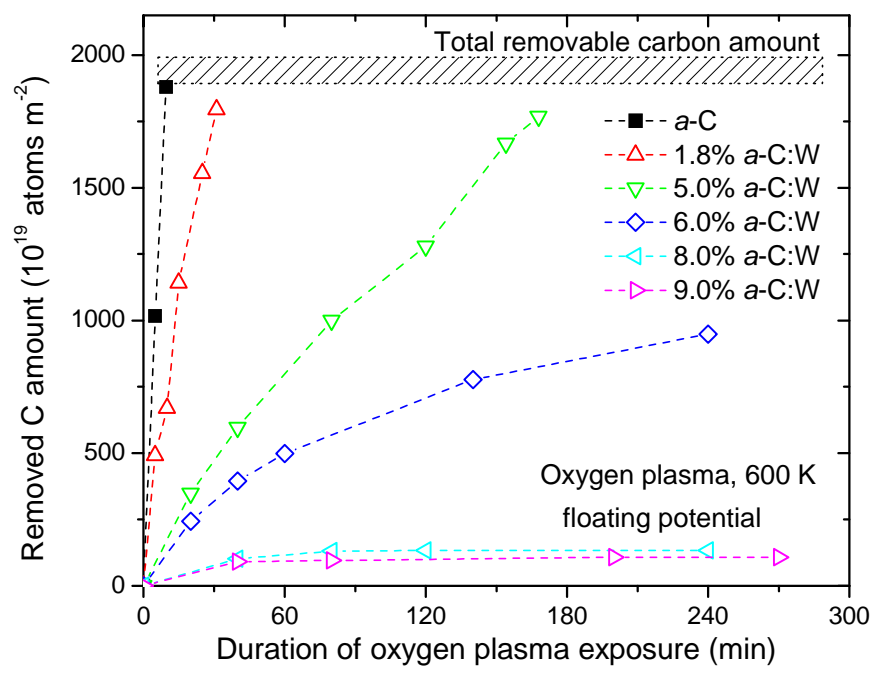

Fig. 5: Removed carbon amount of $a-C: W$ films with different tungsten concentration measured after different erosion durations. For each measured point, a $200 \mathrm{~nm}$ thick a$C: W$ film was eroded at floating potential and $600 \mathrm{~K}$ sample temperature in an oxygen plasma. The total removable carbon amount of the films is marked in the graph as a shaded area (the total carbon amount in the different samples varies slightly due to the difference in $W$ concentration and thickness).

To study the effect of the tungsten concentration on the erosion of $a-\mathrm{C}: \mathrm{W}$ films, about $200 \mathrm{~nm}$ thick pure carbon and $a-\mathrm{C}: \mathrm{W}$ films with different tungsten concentrations were eroded in an oxygen plasma at floating potential. These experiments were also carried out at a sample temperature of $600 \mathrm{~K}$. In Fig. 5 the removed carbon amount is plotted as a function of the duration of plasma exposure. In addition, the total carbon amount in the films is marked by the shaded area. Obviously, all carbon atoms in the $200 \mathrm{~nm}$ thick pure carbon films can be completely removed. The erosion takes less than 10 minutes and corresponds to a $\mathrm{C}$ removal rate of $3.4 \times 10^{19}$ atoms $\cdot \mathrm{m}^{-2} \cdot \mathrm{s}^{-1}$. The time needed for complete carbon removal increases to 30 and 170 min for $1.8 \%$ and $5.0 \%$ $a-\mathrm{C}: \mathrm{W}$ films, respectively. For $6 \% a-\mathrm{C}: \mathrm{W}$ films, only $50 \%$ carbon atoms are removed in 240 minutes and the data indicate a continuous decrease of the erosion rate. For even higher tungsten concentrations in the films ( $8 \%$ and $9 \%)$, the carbon removal clearly saturates, i.e., the removed carbon amount does not change any more after $80 \mathrm{~min}$ suggesting that the residual carbon is shielded by a W-rich layer from further erosion. The significant difference between the films with 5,6 and $8 \% \mathrm{~W}$ indicates that in this concentration range a substantial change of the erosion behavior occurs. Obviously, at $\mathrm{W}$ concentrations of $8 \%$ and higher a compact W-rich layer forms at the surface that blocks further erosion of carbon. 


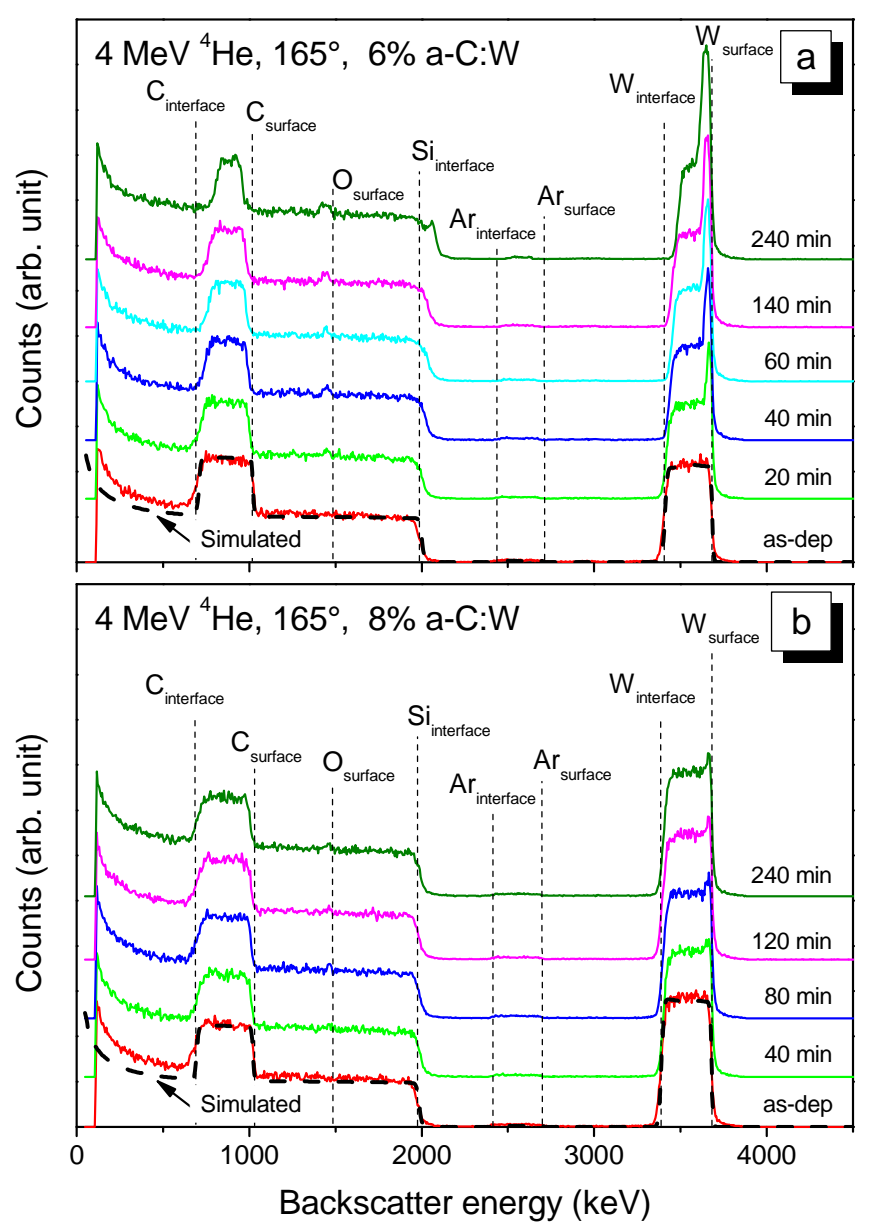

Fig. 6: RBS spectra of a-C:W films with $6 \%$ (a) and $8 \%$ (b) tungsten concentration after exposure to an oxygen plasma at floating potential and $600 \mathrm{~K}$ sample temperature for different durations. The exposure durations are indicated. Simulated spectra for both asdeposited films are also presented.

Fig. 6 shows a series of $4 \mathrm{MeV}^{4} \mathrm{He}$ RBS spectra of the $6 \%$ (a) and $8 \%$ (b) $a-\mathrm{C}: \mathrm{W}$ films leading to the data points in Fig. 5. The composition of the films before and after erosion is obtained by fitting the RBS spectrum with SIMNRA [20]. Examples of fitted spectra are shown as dashed lines for the "as-deposited" film in Figs. 6a and b. Each peak in these RBS spectra corresponds to a certain element as indicated in Fig. 6. The peak height in these RBS spectra corresponds to the local concentration of the element and the integral corresponds to the total areal density. The peak at the highest backscatter energies corresponds to tungsten in the films. The high energy flank of the peak is due to $\mathrm{W}$ atoms at the surface and is marked as $\mathrm{W}_{\text {surface }}$ in the figure. The low energy flank is accordingly due to $\mathrm{W}$ at the interface to the silicon substrate and is marked as $\mathrm{W}_{\text {interface. }}$ The width of the peak contains information on the film thickness and the intensity is correlated to the local concentration in a certain depth. The slightly decreasing peak height of the "as-deposited" film indicates that the distribution of W in the film is not perfectly homogeneous, but that the $\mathrm{W}$ concentration increases slightly from the interface towards the surface. This increase is determined by fitting the spectra. In general it is small and varies for the different $\mathrm{W}$ concentrations. The smallest variation found is $3 \%$, the largest $8 \%$. This number must not be confused with the total $\mathrm{W}$ concentration in the film; it means that the local $\mathrm{W}$ concentration at the interface is by 3 to $8 \%$ lower than the local $\mathrm{W}$ concentration at the surface. It is attributed to a 
small drift during the deposition process. This small inhomogeneity of the $\mathrm{W}$ concentration is only of minor relevance and does not influence our results and interpretations. After erosion the intensity of the $\mathrm{W}$ peak increases at the high energy side. This is due to accumulation $\mathrm{W}$ at the sample surface. Towards lower backscattering energy the next obvious feature in the spectra is due to silicon at the interface $\left(\mathrm{Si}_{\text {interface }}\right.$, around $\left.2000 \mathrm{keV}\right)$. On top of the silicon signal (around $1000 \mathrm{keV}$ ) the carbon signal is found and again, the high energy flank corresponds to $\mathrm{C}$ at the surface and the low energy one to $\mathrm{C}$ at the interface. After erosion additionally an oxygen signal is observed at around $1500 \mathrm{keV}$. A further very small, but clearly discernible signal is found around $2500 \mathrm{keV}$. This is due to argon which is implanted into the $a-\mathrm{C}: \mathrm{W}$ film during magnetron sputtering. The signal corresponds to an argon concentration of about $1 \%$.

The initial thickness of the $6 \%$ a-C:W film (Fig. 6a) was $207 \pm 15 \mathrm{~nm}$ (measured by profilometry). The comparison of the RBS spectra of "as-deposited" and eroded $6 \% a$ $\mathrm{C}: \mathrm{W}$ (Fig. 6a) films yields the following results: Increasing erosion leads to an increase of the $\mathrm{W}$ signal at the film surface while the $\mathrm{W}$ signal of the plateau remains unchanged. In addition, increasing erosion time leads to a shift of the low energy flank of the $\mathrm{W}$ peak towards higher energy. This shift is caused by the erosion of carbon from the film which leads to a thinner film and accordingly to less stopping. The amount of $\mathrm{W}$ remains, however, unchanged. This means that no $\mathrm{W}$ is sputtered during this experiment. The Si edge shifts to higher energies. This is the same effect as discussed for the left flank of the $\mathrm{W}$ peak. Carbon removal due to the erosion process leads to a smaller energy loss of the projectiles and consequently the Si edge shifts to higher energies. For the carbon peak, it is obvious that the peak integral decreases significantly with increasing erosion time. In contrast to $\mathrm{W}$ both flanks of the $\mathrm{C}$ peak shift. The high energy flank which corresponds to $\mathrm{C}$ at the surface shifts to lower energy and the low energy flank to higher energy while the signal height of the peak plateau remains unchanged. The shift of the low energy flank is due to the decrease in total film thickness and has the same origin as the shift of the low energy flank of the W peak and the shift of the Si edge. On the other hand, the shift of the high energy flank of the $\mathrm{C}$ peak to lower energy means that $\mathrm{C}$ is no longer present at the sample surface. This is interpreted as a complete removal of $\mathrm{C}$ from the $\mathrm{W}$-enriched layer at the surface.

We also find increasing amounts of oxygen. Due to the low cross-section for backscattering the signal is very low. Since furthermore the cross-section is not well known for our conditions, the RBS signal cannot be used for a reliable quantification of the oxygen amount. But obviously the $\mathrm{O}$ peak does not have a width which is comparable to the width of the $\mathrm{C}$ and $\mathrm{W}$ peaks. But the width of the $\mathrm{O}$ peak is in reasonable agreement with the width of the $\mathrm{W}$ enrichment layer at the surface. We, therefore, assume that significant amounts of oxygen are present only in the W-rich layer. Detailed fitting of the RBS spectra using SIMNRA [20] confirms in general the interpretations outlined above. However, the height and width of the $\mathrm{W}$ peak corresponding to the W-rich layer at the surface can only be fitted assuming the presence of another atomic species in this layer. Good agreement is achieved if we assume that this species is oxygen. Actually, in most of the investigated W-rich layers, the concentration ratio of tungsten and oxygen determined by this fitting ranges from 2.8 to 3.5. Considering the uncertainty of the RBS analysis this result is in agreement with the formation of a layer of $\mathrm{WO}_{3}$ at the surface of the films. The areal density of $\mathrm{W}$ and $\mathrm{O}$ atoms in the $\mathrm{W}$ oxide layer for this $6 \% a-\mathrm{C}: \mathrm{W}$ film after $240 \mathrm{~min}$ plasma exposure is $1.82 \times 10^{21}$ atoms $/ \mathrm{m}^{2}$ and it consists of $22 \%$ tungsten and $78 \%$ oxygen. If bulk density of $\mathrm{WO}_{3}\left(7.16 \mathrm{~g} \mathrm{~cm}^{-3}\right.$ [30]) is assumed this would correspond to a thickness of $98 \mathrm{~nm}$. But, as discussed before, this layer cannot be dense but must be sufficiently 
porous to allow transport of reactive species from the plasma to the carbon and transport of the released erosion products from the carbon interface to the surface. Accordingly the real thickness should be significantly higher.

The spectral features of the $8 \% a-\mathrm{C}: \mathrm{W}$ films (Fig. $6 \mathrm{~b}$ ) are in principal quite similar to those of the $6 \% a-\mathrm{C}: \mathrm{W}$ films. The initial thickness of the $8 \% a-\mathrm{C}: \mathrm{W}$ film was $225 \pm 15 \mathrm{~nm}$ (measured by profilometry). The basic differences are that the $\mathrm{W}$ enrichment at the surface is less pronounced and that the erosion process stops after about 80 min (compare also with Fig. 5). For $8 \%$ a-C:W films, less than $10 \%$ carbon was removed and after $80 \mathrm{~min}$ plasma exposure the areal density of $\mathrm{W}$ in the $\mathrm{W}$-rich layer is $4.2 \times 10^{20}$ atoms $/ \mathrm{m}^{2}$ (corresponding to $22 \mathrm{~nm}$ bulk $\mathrm{WO}_{3}$ ). For further plasma exposure, no measurable changes can be detected. For $8 \% a-\mathrm{C}: \mathrm{W}$ film after $240 \mathrm{~min}$ erosion the concentration of tungsten and oxygen in the W-rich layer is $26 \%$ and $74 \%$, respectively.

As already mentioned above, Davis et al. reported that a sputter-deposited 3-4 nm thick compact tungsten layer on $a-\mathrm{C}: \mathrm{D}$ films completely suppresses erosion due to baking in oxygen atmosphere at $623 \mathrm{~K}$ [29]. In our experiments the $\mathrm{W}$ oxide layer for the $6 \% a-\mathrm{C}: \mathrm{W}$ films after 240 min plasma erosion would correspond to $98 \mathrm{~nm} \mathrm{WO}_{3}$ while for the $8 \% a-\mathrm{C}: \mathrm{W}$ films it is only $22 \mathrm{~nm}$ thick. This means that the plasma erosion process stops in $8 \% a-\mathrm{C}$ :W films with a thinner $\mathrm{W}$ oxide layer than for the $6 \%$ $a-\mathrm{C}: \mathrm{W}$ films. Furthermore, in the $6 \% a-\mathrm{C}: \mathrm{W}$ films erosion still continues although the $\mathrm{W}$ oxide layer is significantly thicker than for the $8 \% a-\mathrm{C}$ :W films. Obviously, the structure and morphology of the $\mathrm{W}$ oxide layer for these two types of films differs substantially. We assume that a very porous tungsten oxide layer is formed for the $6 \%$ $a-\mathrm{C}: \mathrm{W}$ films and a more compact structure for $8 \% a-\mathrm{C}: \mathrm{W}$ films.

Cross-sections of plasma-exposed films were investigated with scanning electron microscopy to confirm the surprisingly large thicknesses of the $\mathrm{W}$ oxide layers estimated from the RBS results. Fig. 7 presents an image of the surface of the $6 \%$ film and cross-sections of the $6 \%$ and $8 \% a-\mathrm{C}: \mathrm{W}$ films after 240 min plasma exposure at $600 \mathrm{~K}$. Both films are the identical samples that were used to determine the RBS results presented in Figs. 5 and 6.

The thickness of the $6 \%$ a-C:W film before plasma treatment was $207 \pm 15 \mathrm{~nm}$ (determined by profilometry). It decreased after $240 \mathrm{~min}$ plasma exposure to about $190 \mathrm{~nm}$ (determined by SEM, Fig. 7b, uncertainty about $\pm 5 \mathrm{~nm}$ ). $120 \mathrm{~nm}$ are still original $a-\mathrm{C}: \mathrm{W}$ film and the thickness of the $\mathrm{W}$ oxide layer is about $70 \mathrm{~nm}$. The $8 \% a-$ $\mathrm{C}: \mathrm{W}$ film had an initial thickness of $225 \pm 15 \mathrm{~nm}$. After $240 \mathrm{~min}$ plasma exposure the remaining bulk layer has a thickness of $210 \mathrm{~nm}$ and the $\mathrm{W}$ oxide layer is about $20 \mathrm{~nm}$ thick (Fig. 7c). Both $\mathrm{W}$ oxide films show a rather granular structure with grain sizes of the order of $1 \mathrm{~nm}$ up to several $\mathrm{nm}$. For the $6 \% a-C: \mathrm{W}$ film it appears as if the grains at the surface are smaller than at the interface to the bulk film. It is remarkable that for both films the interface between $\mathrm{W}$ oxide layer and original $a-\mathrm{C}: \mathrm{W}$ layer is relatively sharp. The granular structure of the $\mathrm{W}$ oxide layer is also visible in the image of the surface of the $6 \%$ films shown in Fig. 7 a. 


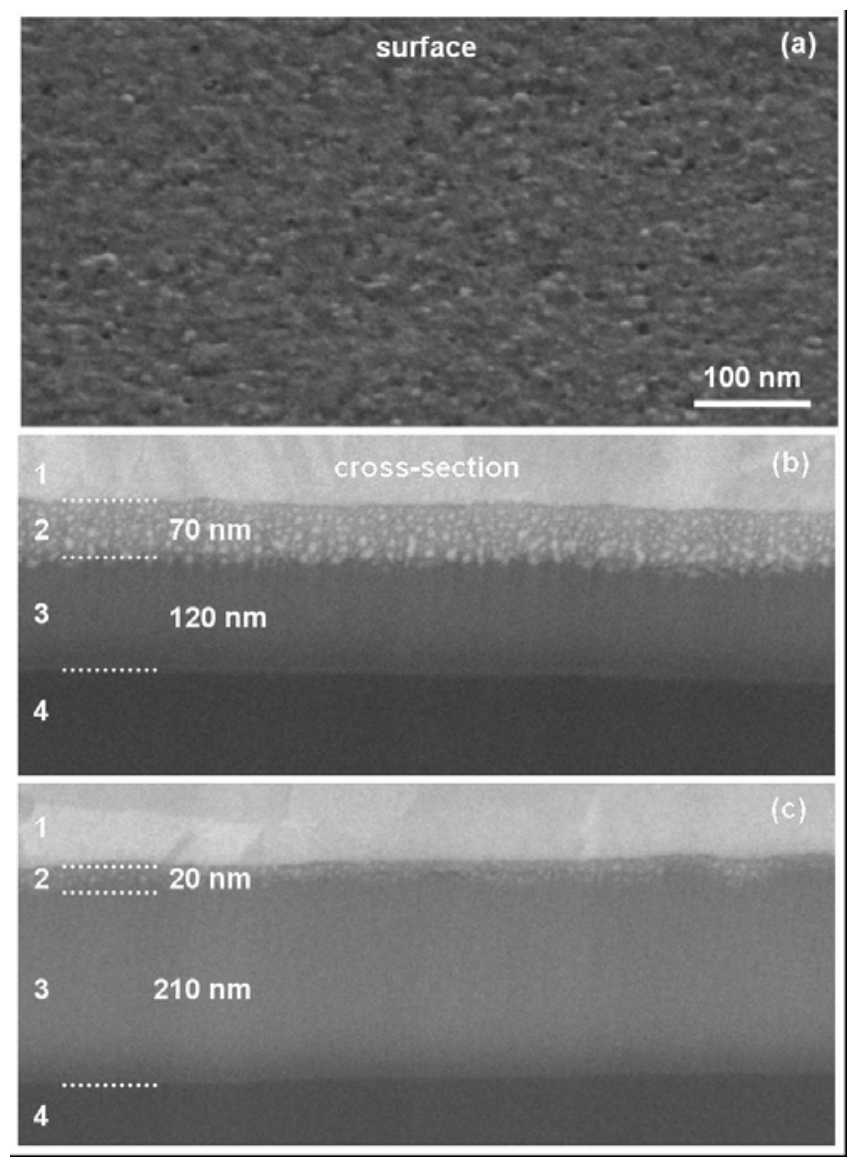

Fig. 7: SEM images of a-C:W films after 240 min oxygen plasma exposure at floating potential and $600 \mathrm{~K}$ sample temperature. (a) Surface image of the $6 \%$ film (the angle between surface normal an electron beam is $52^{\circ}$ for this image). Cross-section images of a $6 \%$ (b) and $8 \%$ a-C:W film (c). The three interfaces between the Cu cover layer (1), the tungsten-enriched layer of the $a-C: W$ film (2), the remaining unchanged $a-C: W$ film (3), and the Si substrate (4) are marked by dotted lines. The thicknesses of the two middle layers are given taking the tilting of $38^{\circ}$ into account.

In principle, these SEM cross-sections confirm qualitatively the interpretation of the RBS result presented above (Figs. 5 and 6), but there are some inconsistencies with respect to a quantitative comparison. The thickness of the $\mathrm{W}$ oxide for the $6 \% a-\mathrm{C}: \mathrm{W}$ sample layer determined by SEM is $70 \mathrm{~nm}$ and that estimated from RBS is $98 \mathrm{~nm}$. Although the two numbers seem to be in acceptable agreement - considering the experimental uncertainties of both methods - the $98 \mathrm{~nm}$ from the RBS data were estimated assuming $\mathrm{WO}_{3}$ bulk density. We have already argued that the $\mathrm{W}$ oxide layer has to be very porous to enable continuous erosion and the SEM cross-sections (Fig. 7) support this assumption. But if the layer has a significant porosity, then the corresponding thickness estimated from the RBS results should be accordingly larger enhancing the disagreement with the SEM-determined thickness. The reason for this obvious inconsistency is presently unclear but it might be at least partially due to problems related to the quantitative evaluation of the RBS spectra of the rough and porous $\mathrm{W}$-oxide layer at the surface of the plasma-treated films. On the other hand, the remaining thickness of the bulk layer of this $6 \% a-\mathrm{C}: \mathrm{W}$ sample is $120 \mathrm{~nm}$ corresponding to about $58 \%$ of the initial thickness. Accordingly, about $58 \%$ of the initial amount of carbon should be found for this film. This is in acceptable agreement with the data shown in Fig. 5 where about $52 \%$ carbon remain for this $6 \% a-\mathrm{C}: \mathrm{W}$ film. The quantitative comparison between RBS and SEM results for the $8 \% a-\mathrm{C}: \mathrm{W}$ sample 
give a similar picture than that for the $6 \% a-C: W$ sample. The two thicknesses $(20 \mathrm{~nm}$ for SEM and $22 \mathrm{~nm}$ for RBS) seem to match, but for the RBS estimate the obvious porosity was not taken into account so that the thickness estimated from RBS should be significantly larger. The decrease of the $a-C: \mathrm{W}$ bulk layer thickness from about $225 \mathrm{~nm}$ (determined for the as deposited sample by profilometry) to about $210 \mathrm{~nm}$ (SEM, Fig. 7) is in reasonable agreement with the decrease of the carbon amount determined by RBS (Fig. 5). In summary, the SEM cross-sections confirm that the $\mathrm{W}$ oxide layers formed during plasma exposure are surprisingly thick and porous and that higher initial W concentrations lead to thinner $\mathrm{W}$ oxide layers.

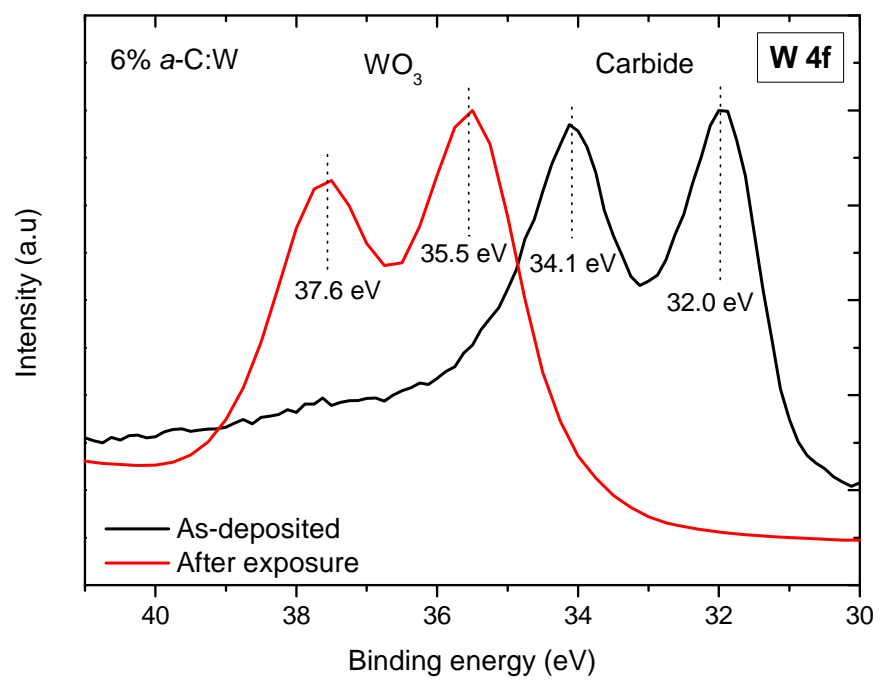

Fig. 8: XPS $W 4 f$ spectra of $6 \%$ a-C:W film before and after 240 min oxygen plasma exposure at floating potential and $600 \mathrm{~K}$ sample temperature. To remove the absorbate layer, both films were sputtered by $3 \mathrm{keV} \mathrm{Ar}^{+}$ion beam for 1 minute.

To study the chemical bonding and composition depth profile of the W-rich layers, $\mathrm{C}$ 1s, W 4f, O 1s and Si 2p peaks were investigated with XPS. As known from previous studies [19,32] all $\mathrm{W}$ in these magnetron sputtered a-C:W films is in the carbidic state and annealing does not change this. Fig. 8 shows the $\mathrm{W} 4 \mathrm{f}$ core-level doublet spectra of an as-deposited $6 \% a-\mathrm{C}: \mathrm{W}$ film before and after oxygen plasma exposure at floating potential and $600 \mathrm{~K}$ sample temperature. The spectrum of the as-deposited film consists of a doublet at binding energies of $34.1 \mathrm{eV}$ for the $\mathrm{W} 4 \mathrm{f}_{5 / 2}$ and $32.0 \mathrm{eV}$ for the $\mathrm{W} 4 \mathrm{f}_{7 / 2}$, corresponding to tungsten in the carbide state [31]. Unfortunately, it is not possible to determine which kind of carbide is formed in the film because the binding energy difference between $\mathrm{WC}\left(\mathrm{W}_{4 / 2} 32.2 \mathrm{eV}\right)$ and $\mathrm{W}_{2} \mathrm{C}\left(\mathrm{W} 4 \mathrm{f}_{7 / 2} 31.8 \mathrm{eV}\right)$ is too small to allow a safe assignment [18,32]. After 4 hours oxygen plasma exposure at floating potential and $600 \mathrm{~K}$ sample temperature, the $\mathrm{W} 4 \mathrm{f}_{5 / 2}$ peak shifts to $37.6 \mathrm{eV}$ and the $\mathrm{W} 4 \mathrm{f}_{7 / 2}$ peak to $35.5 \mathrm{eV}$. This doublet is assigned to $\mathrm{WO}_{3}[33,34]$. These results demonstrate that $\mathrm{W}$ is present in form of tungsten carbide in the as-deposited films. After plasma erosion carbon is removed from the surface-near region and $\mathrm{W}$ is oxidized and is present in form of $\mathrm{WO}_{3}$. 


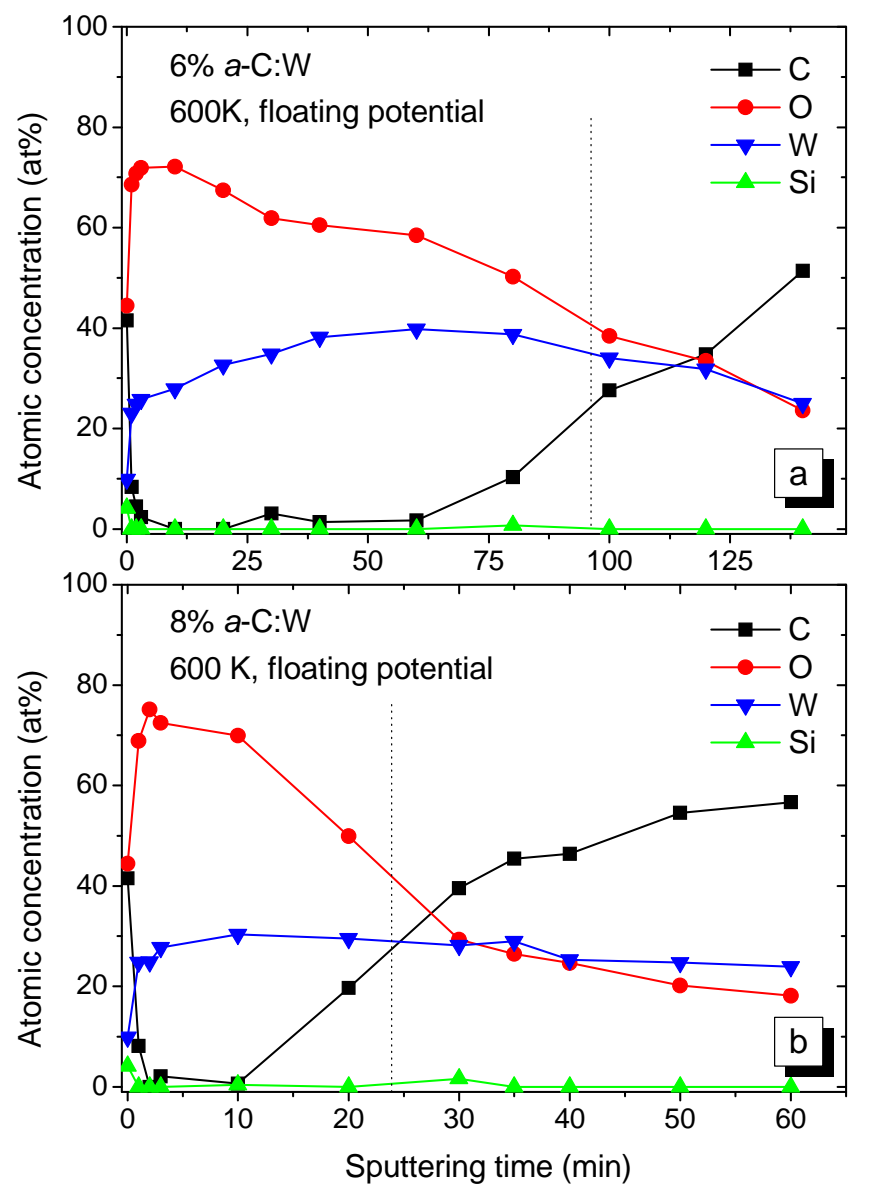

Fig. 9: Depth profile of carbon, oxygen, tungsten and silicon for $6 \%$ (a) and $8 \%$ (b) aC:W films after 240 min oxygen plasma exposure at floating potential and $600 \mathrm{~K}$ sample temperature. The vertical lines indicate the position of the interface between the $\mathrm{WO}_{3}$ layer and the bulk of the a-C:W film.

Fig. 9 presents XPS depth profiles of $6 \%$ (a) and $8 \%$ (b) $a$-C:W films after 4 hours oxygen plasma exposure at floating potential and $600 \mathrm{~K}$ sample temperature. Both films show apart from tungsten and oxygen a relatively high carbon content at the surface. This is attributed to adsorbed carbon due to exposure to ambient air prior to XPS analysis. Already after 1 minute $\mathrm{Ar}^{+}$sputtering (at $3.0 \mathrm{keV}$ ) most of the adsorbed carbon layer is removed and after 2 to $3 \mathrm{~min}$ sputtering it is completely gone. After removal of the adsorbate layer the XPS spectra show only tungsten and oxygen signals. The ratio of oxygen to tungsten at the initial surface is about 4.5 , this value is more than 3 (the ratio of $\mathrm{WO}_{3}$ ) because oxygen is not only bonded to tungsten but also contained in the adsorbate layer. The ratio of oxygen to tungsten drops to 3 after 1 minute $\mathrm{Ar}^{+}$ sputtering. This is in good agreement with the binding energies presented in Fig. 8 and with the evaluation of the RBS data. The ratio of oxygen to tungsten decreases with further increasing sputtering time most probably due to preferential sputtering of oxygen. Because the sputter yields of the porous $\mathrm{WO}_{3}$ are not known, we cannot convert the sputter time scale to a depth scale. If we define the interface between the $\mathrm{W}$ oxide layer and the original film by the increase of the carbon signal to $50 \%$ of the bulk value, then the corresponding sputtering times are about 95 and $23 \mathrm{~min}$ for the $6 \%$ and $8 \% a-\mathrm{C}: \mathrm{W}$ films. The ratio between these two numbers is 4.1. It is in reasonable agreement with the ratio of the total tungsten amounts in the enriched layers determined 
by RBS which is 4.5 (see discussion of RBS result above). Therefore, the XPS results support the supposition made on basis of the RBS data that the W-rich layer formed after oxygen plasma exposure consists of $\mathrm{WO}_{3}$ oxide. The fact that the carbon to tungsten ratio in the bulk of the $a-\mathrm{C}: \mathrm{W}$ film (Fig. $9 \mathrm{~b}$ ) is not equal to the $\mathrm{W}$ concentration measured by RBS is due to preferential sputtering of $\mathrm{C}$ which causes enrichment of $\mathrm{W}$ at the surface during depth profiling. Because XPS is very surface sensitive, the $\mathrm{W}$ enrichment leads to a higher XPS signal and does not reflect the bulk value.

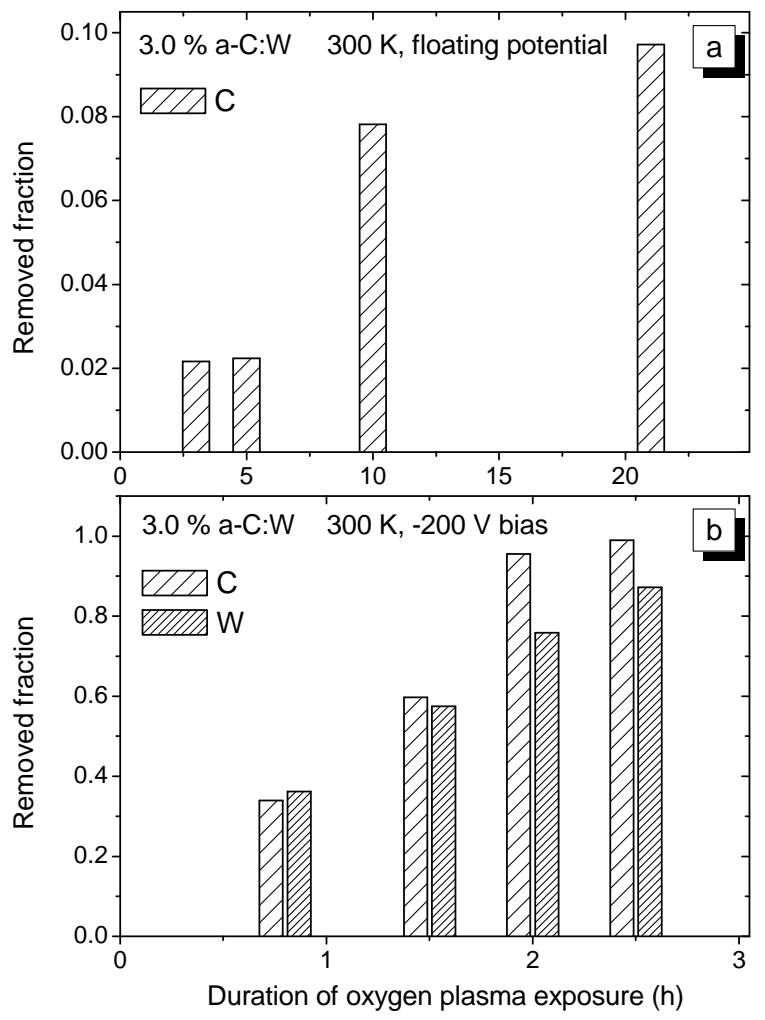

Fig. 10: Fraction of carbon and tungsten removed from $500 \mathrm{~nm}$ thick $3 \%$ a-C:W films as a function of the erosion duration at floating potential (a) and $-200 \mathrm{~V}$ dc self-bias voltage (b) in oxygen plasma. At floating potential, the ion energy is too low for physical sputtering of $W$ by $O$, consequently, no $W$ is sputtered in this case.

Fig. 10 shows the ratio of the removed carbon and tungsten amounts to the corresponding total amounts of $500 \mathrm{~nm}$ thick $3 \% a-\mathrm{C}: \mathrm{W}$ films as a function of the erosion duration at floating potential (a) and at $-200 \mathrm{~V}$ dc self-bias voltage (b). In this experiment, the cooled substrate holder was used to ensure that the erosion takes place at room temperature. At room temperature chemical erosion is very inefficient (see Fig. 3) and consequently the erosion rates are very low. At floating potential the removed carbon amount increases slowly with increasing erosion duration. Only about $10 \%$ of the carbon atoms in the film were removed after 21 hours exposure to oxygen plasma. The time-averaged erosion rates for the 10 and $21 \mathrm{~h}$ plasma exposure are $1.24 \times 10^{18}$ atoms $\cdot \mathrm{m}^{-2} \cdot \mathrm{s}^{-1}$ and $5.8 \times 10^{17}$ atoms $\cdot \mathrm{m}^{-2} \cdot \mathrm{s}^{-1}$, respectively. As expected, the $\mathrm{W}$ concentration at the surface of these films increases with increasing exposure time, but the total tungsten amount obtained by integrating the tungsten peaks does not change. I.e., no tungsten atoms are removed during plasma erosion at floating potential. On the other hand, with $-200 \mathrm{~V}$ rf bias, most of the tungsten atoms and all carbon atoms in the films are removed within 2.5 hours. At $-200 \mathrm{~V}$ bias, although $\mathrm{W}$ atoms will enrich at the 
surface due to preferential erosion of carbon, $\mathrm{W}$ atoms are continuously removed from the surface by physical sputtering because the incident oxygen ions have an energy above the threshold for physical sputtering of tungsten by oxygen (about $44 \mathrm{eV}$ ) [27]. As a result, biasing the sample to $-200 \mathrm{~V}$ inhibits the formation of a thick protecting $\mathrm{W}$ oxide layer and the complete film can be removed.

\section{Conclusion}

The erosion behavior of tungsten-doped carbon films in low-temperature oxygen plasmas was studied. The erosion of $a-\mathrm{C}: \mathrm{W}$ films depends sensitively on the film composition and the erosion conditions. The erosion rate of $a-\mathrm{C}: \mathrm{W}$ films is clearly lower than the rate of pure amorphous carbon film and increases with the increase of ion energy (biasing) and substrate temperature. The erosion rates of $a-\mathrm{C}: \mathrm{W}$ films decrease strongly with increasing tungsten concentration. Addition of only 1.8 at.\% W leads to a reduction of the $\mathrm{C}$ removal rate at $300 \mathrm{~K}$ by almost a factor of 6 compared with a pure carbon film. Furthermore, they decrease with increasing exposure duration because carbon is preferentially eroded while tungsten atoms accumulate and oxidize at the surface leading to the formation of protective W-rich layer. The temperature dependence shows an Arrhenius-type increase of the erosion rates with increasing sample temperature with an apparent activation energy of $0.09 \mathrm{eV}$ for the pure amorphous carbon film and $0.17 \mathrm{eV}$ for the $1.8 \% a-\mathrm{C}: \mathrm{W}$ film.

RBS and XPS analyses consistently show that the W-rich layer that forms at the surface after oxygen plasma exposure at low bias voltage consists of $\mathrm{WO}_{3}$. We speculate that the morphology of this layer formed during erosion at low ion energy depends strongly on the initial $\mathrm{W}$ concentration in the films. It is more compact but thinner for films with higher initial tungsten concentration ( $8 \%$ and higher). For $\mathrm{W}$ concentrations of $8 \%$ and higher it blocks the transmission of reactive oxygen species and/or the release of the erosion products and prevents further erosion. Only applying a sufficiently high bias voltage to enable physical sputtering to remove the $\mathrm{W}$ oxide layer from the surface allows continuous removal of such films.

As a consequence, our results indicate that for efficient removal of $\mathrm{W}$-containing carbon films with $\mathrm{W}$ concentrations higher than about $8 \%$ by oxygen glow discharge cleaning procedures intense ion bombardment of the respective surface is required. This can only be achieved on plasma-facing surfaces. On the other hand, it is presently not assumed that $\mathrm{W}$ migrates to remote areas. Therefore, we don't have to assume that redeposited layers in remote areas will contain high $\mathrm{W}$ concentrations. Although the film removal rate is significantly reduced due to $\mathrm{W}$ addition, films with low $(<8 \%) \mathrm{W}$ concentrations can still be removed even without energetic ion bombardment.

\section{Acknowledgments}

The stay of P. Wang at Max-Planck Institute for Plasma Physics in Garching was funded through a bilateral agreement between Max-Planck Society and the Chinese Academy of Sciences which is gratefully acknowledged. Thanks are further due to Till Hoeschen for help with the XPS measurements. 


\section{References}

[1] J. Roth, E. Tsitrone, T. Loarer, V. Philipps, S. Brezinsek, A. Loarte, G. F Counsell, R. P Doerner, K. Schmid, O. V Ogorodnikova, R. A Causey, Plasma Phys. Control. Fusion 50 (2008) 1.

[2] W. Jacob, J. Nucl. Mater. 337-339 (2005) 839.

[3] G. Federici, C.H. Skinner, J. N. Brooks, et al., Nucl. Fus. 41 (2001) 1967.

[4] C. Hopf, V. Rohde, W. Jacob, A. Hermann, R. Neu, J. Roth, J. Nucl. Mater. 363-365 (2007) 882.

[5] J. S. Hu, J. G. Li, X. M. Wang, Plasma Phys. Control. Fusion 47 (2005) 1271.

[6] J. S. Hu, J. G. Li, X. M. Wang, Y. P. Zhao, and HT-7 Team, J. Nucl. Mater., 363-365, (2007) 862.

[7] M. J. Rubel, G. D. Temmerman, G. Sergienko, P. Sundelin, B. Emmoth, V. Philipps, J. Nucl. Mater. 363-365 (2007) 877.

[8] V. Philipps, G. Sergienko, A. Lyssoivan, H. G. Esser, M. Freisinger, A. Kreter, U. Samm, J. Nucl. Mater. 363-365 (2007) 929.

[9] J. W. Davis, A. A. Hassz, J. Nucl. Mater. 390-391 (2009) 532.

[10] C. Grisolia, G. Counsell, G. Dinescu, A. Semerok, N. Bekris, P. Coad, C. Hopf, J. Roth, M. Rubel, A. Widdowson, E. Tsitrone, Fusion Eng. Des. 82 (2007) 2390.

[11] T. Schwarz-Selinger, F. Genoese, C. Hopf, W. Jacob, J. Nucl. Mater. 390-391 (2009) 602.

[12] T. Schwarz-Selinger, U. V. Toussaint, C. Hopf, W. Jacob, Phys. Scr. 138 (2009) 014009.

[13] M. Balden, C. Adelhelm, Phys. Scr. T128 (2007) 121.

[14] M. Balden, E. de Juan Pardo, I. Quintana, B, Cieciwa, J. Roth, J. Nucl. Mater. 337-339 (2005) 980.

[15] C. Hopf, W. Jacob, V. Rohde, J. Nucl. Mater. 374 (2008) 413.

[16] W. Jacob and J. Roth, Chemical Sputtering, in Sputtering by Particle Bombardment IV, R. Behrisch and W. Eckstein (Eds.), Springer Verlag, Berlin, 2007, pp. 329-400.

[17] M. Balden, B. T. Cieciwa, I. Quintana, E. de Juan Pardo, F. Koch, M. Sikora, B. Dubiel, Surf. Coat. Technol. 200 (2005) 413.

[18] M. Balden, P.A. Sauter, S. Jong, C. Adelhelm, S. Lindig, M. Rasinski, T. Plocinski, Thin Solid Films 519 (2011) 4049-4053.

[19] C. Adelhelm, Ph.D Thesis, "Structure and Erosion Behavior of Metal-doped Carbon Films", Tech. Report IPP 17/11, Max-Planck-Institut für Plasmaphysik (2008).

[20] M. Mayer, SIMNRA User's Guide, Tech. Report IPP 9/113, Max-Planck-Institut für Plasmaphysik, Garching, 1997.

[21] B. Landkammer, A. von Keudell, W. Jacob, J. Nucl. Mater. 264 (1999) 48.

[22] A. Manhard, T. Schwarz-Selinger, W. Jacob, Plasma Sources Sci. Technol. 20 (2011) 015010.

[23] O.V. Ogorodnikova, T. Schwarz-Selinger, K.Sugiyama, V.Kh. Alimov, J. Appl. Phys. 109, (2011) 013309 .

[24] Trademark by Advanced Ceramics Corporation Lakewood, OH 44107, Distributed by tectra GmbH, Reuterweg 65, D-60323 Frankfurt/Main.

[25] J. Robertson, Mater. Sci. Eng. Reports 37 (2002) 129.

[26] C. Adelhelm, M. Balden, M. Rinke, M. Stueber, J. Appl. Phys. 105 (2009) 033522.

[27] W. Eckstein, Sputtering Yields in Sputtering by Particle Bombardment IV, R. Behrisch and W. Eckstein (Eds.), Springer Verlag, Berlin, 2007, p 142.

[28] M. Balden, K.U. Klages, W. Jacob, J. Roth, J. Nucl. Mater. 341 (2005) 31.

[29] J. W. Davis, C. G. Hamilton, A. A. Hassz, R. G. Macaualy-Newcombe, J. Nucl. Mater. 305 (2002) 66.

[30] S. H. Lee, R. Deshpande, P. A. Parilla, et al., Adv. Mater. 18 (2006) 763.

[31] J. Luthin, Ch. Linsmeier, Surf. Sci. 454-456 (2000) 78.

[32] C. Adelhelm, M. Balden, M. Rasinski, Surf Coatings Tech 205 (2011) 4335-4342.

[33] A. Siokou, G. Leftheriotis, S. Papaefthimiou, P. Yianoulis, Surf. Sci. 482-485 (2001) 294.

[34] A. Romanyuk, V. Melnik, P. Oelhafen, Nucl. Instrum. Meth. B 232 (2005) 358-361. 